\title{
5-aminolevulinate dehydratase activity in blood of rabbits given tin or lead
}

\author{
MOMOKO CHIBA AND MASAKAZU KIKUCHI \\ From the Department of Hygiene, Juntendo University School of Medicine, Tokyo 113, Japan
}

ABSTRACT The activity of 5-aminolevulinate dehydratase (ALAD) in rabbit blood is significantly inhibited by tin. Intravenous administration of tin $(0.48$ or $4.8 \mu \mathrm{mol} / \mathrm{kg}$ body weight) causes a decrease in the activity of the enzyme by $60 \%$ or $94 \%$ respectively. The effects of tin and lead on ALAD differ: inhibition by tin is not affected by pre-incubation at $50-60^{\circ} \mathrm{C}$, whereas the inhibitory effect of lead is increased by the same pretreatment. The optimum $\mathrm{pH}$ for rabbit blood ALAD is 6.8 in control rabbits. This optimum shifts to $\mathrm{pH} \mathrm{5.8-6.0} \mathrm{in} \mathrm{the} \mathrm{blood} \mathrm{of} \mathrm{tin-treated}$ rabbits, with or without pre-incubation at $60^{\circ} \mathrm{C}$ for $5 \mathrm{~min}$, while a similar shift is prevented by the same pre-incubation after lead treatment. Recovery to normal activity is faster after tin than after lead treatment.

A fall in the activity of 5-aminolevulinate dehydratase (ALAD) [5-aminolevulinate hydro-lyase, EC 4.2.1.24] in blood is the most sensitive index of lead exposure (De Bruin and Hoolboom, 1967; Hernberg et al., 1972). However, we have found that the activity of this blood enzyme is also inhibited by inorganic tin. This fact must be considered when the activity of ALAD is measured during the medical examination of lead-exposed workers. The present report deals with the effect of tin on ALAD activity in rabbit blood and suggests a method for discriminating between the effects of tin and lead on this enzyme.

\section{Materials and methods}

\section{ANIMALS}

Four groups of adult male rabbits (New Zealand White) of $2 \cdot 5-3.0 \mathrm{~kg}$ body weight were used. Each group consisted of four rabbits.

\section{METAL SOLUTIONS}

Stannous chloride $\left(\mathrm{SnCl}_{2} \cdot 2 \mathrm{H}_{2} \mathrm{O}\right)$ and lead acetate $\left[\mathrm{Pb}\left(\mathrm{CH}_{3} \mathrm{COO}\right)_{2} \cdot 3 \mathrm{H}_{2} \mathrm{O}\right]$ were each dissolved in $5 \%$ glucose.

DOSE AND ROUTE OF ADMINISTRATION Group A (control) received $5 \%$ glucose; Group B (Pb) received 4.8 $\mu \mathrm{mol} \mathrm{Pb/kg;} \mathrm{Group} \mathrm{C} \mathrm{(low} \mathrm{Sn}$ )

Received for publication 7 July 1978 Accepted for publication 21 March 1979 received $0.48 \mu \mathrm{mol} \mathrm{Sn} / \mathrm{kg}$ and Group D (high $\mathrm{Sn}$ ) received $4.8 \mu \mathrm{mol} \mathrm{Sn} / \mathrm{kg}$. Each animal was injected with $0.5 \mathrm{ml} / \mathrm{kg}$ body weight via the marginal ear vein once a day for three consecutive days.

\section{BLOOD SAMPLING}

Blood drawn from the marginal ear vein was haemolysed by freezing on solid carbon dioxide. Heparin was used as an anticoagulant agent. About $1 \mathrm{ml}$ of blood was collected from the marginal vein on the 1st, 2nd, 3rd, 6th, 9th, 14th, 23rd, 37th, and 55 th days after the first injection. On the 1st and 3rd days an additional 2-4 ml of blood was collected for experiments on the effect of heat treatments or on the $\mathrm{pH}$ dependency.

\section{ASSAY FOR ALAD ACTIVITY}

ALAD activity was assayed according to the method of Chiba et al. (1976). ALAD activity was represented by absorbance at $556 \mathrm{~nm}\left(\mathrm{~A}_{556}\right)$ or $\mu \mathrm{mol}$ porphobilinogen (PBG) formed. The effect of heat treatment on ALAD activities was estimated from differences in values without and after pre-incubation at $40^{\circ}$, $50^{\circ}$, or $60^{\circ} \mathrm{C}$. The method of Nikkanen et al. (1972) was used to study $\mathrm{pH}$ dependency. All determinations were carried out in duplicate.

\section{Results}

EFFECT OF TIN OR LEAD ON ALAD ACTIVITY

ALAD activities determined on the 1st, 2nd, 3rd, 


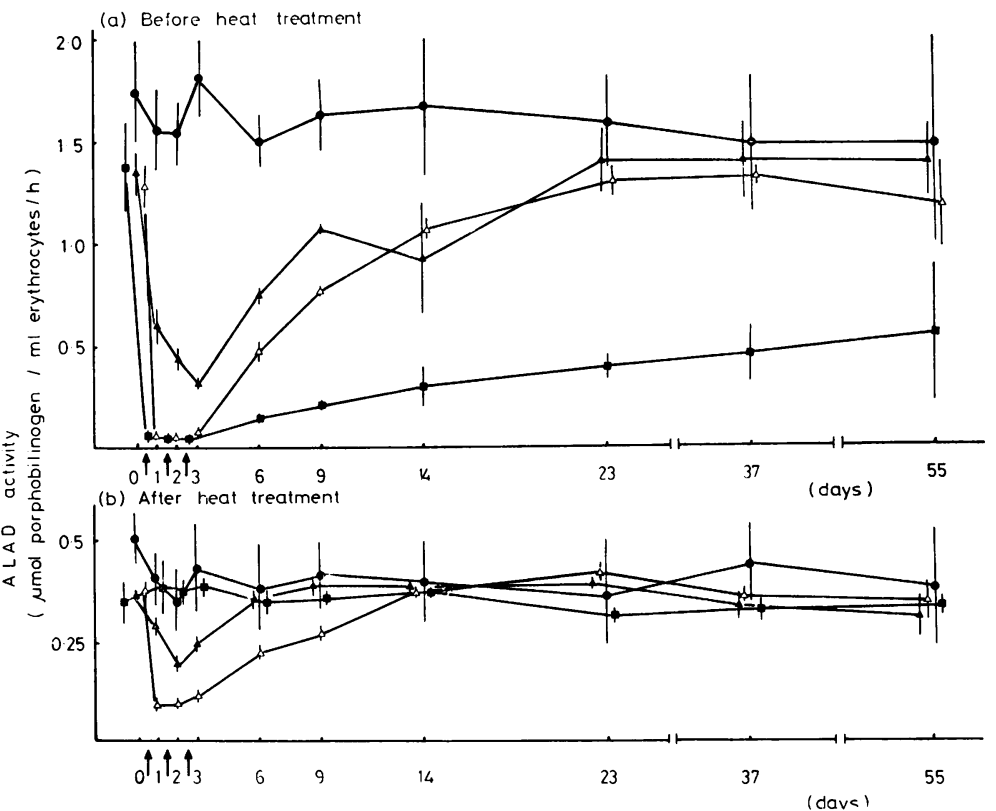

Fig. $1 A L A D$ activity before and after heat treatment at $60^{\circ} \mathrm{C}$ for $5 \mathrm{~min}$ in blood from rabbits injected iv with lead or tin. Group $A$ (control); Group $B$ $(4.8 \mu \mathrm{mol} \mathrm{Pb} / \mathrm{kg}) ; \Delta$ Group $C(0.48 \mu \mathrm{mol} \mathrm{Sn} / \mathrm{kg}) ; \triangle$ Group D $(4.8 \mu \mathrm{mol}$ $S n / k g) ; \uparrow$ Injection: $\mid \pm S D$.

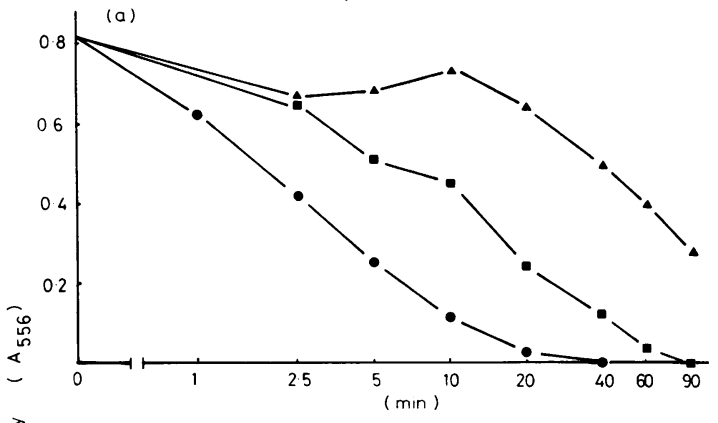

6th, 9th, 14th, 23rd, 37th, and 55th days after the first injection are shown in Fig. 1. It can be seen that ALAD activity decreased significantly after a single injection in Groups B, C, and D $(P<0.01)$. In tintreated animals (Groups $C$ and $D$ ) activities became normal soon after the cessation of treatment, whereas recovery in the lead-treated animals (Group
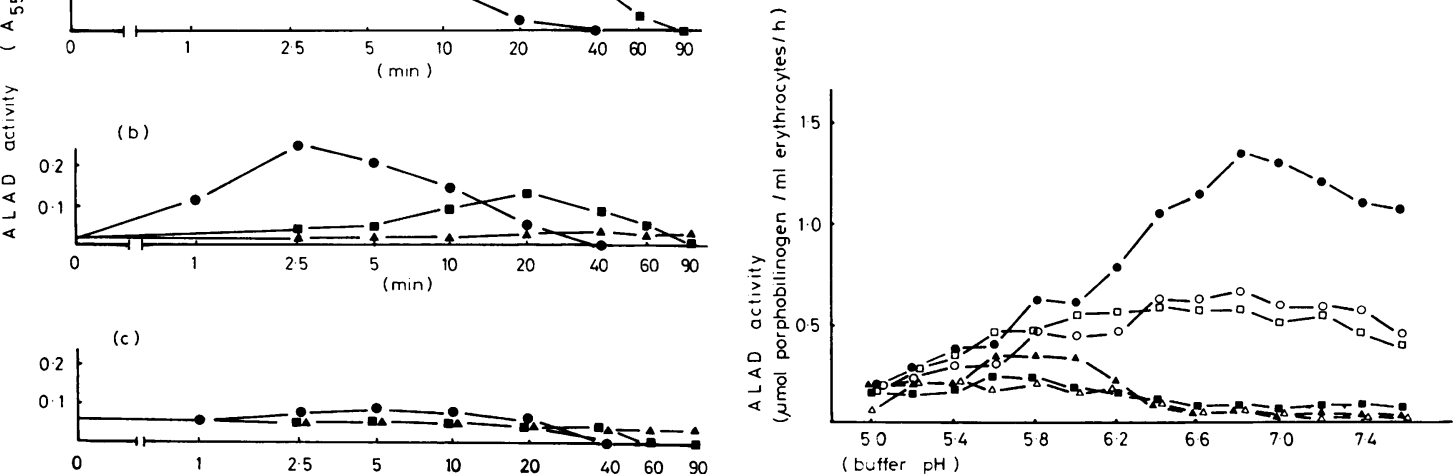

Fig. 2 Effect of temperature and duration of pre-incubation on ALAD activity in rabbit blood. (a) Group A (control); (b) Group B $(4 \cdot 8 \mu \mathrm{mol} \mathrm{Pb/kg}$ iv); (c) Group D (4.8 $\mu \mathrm{mol} \mathrm{Sn/kg} \mathrm{iv).} \mathrm{Blood} \mathrm{samples}$ were collected on the first day after single injection. Heat treatment: $60^{\circ} \mathrm{C}(\mathrm{O}) ; 50^{\circ} \mathrm{C}(\square) ; 40^{\circ} \mathrm{C}(\mathbf{\Delta})$.

Fig. $3 \mathrm{pH}$ dependency of $A L A D$ activity in rabbit blood. Blood was from Group A (control) (O), Group B

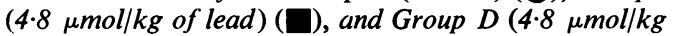
of tin) ( $\mathbf{\Delta})$. Blood was collected on the 3rd day after the first injection. Open symbols represent values after 5 min pre-incubation at $60^{\circ} \mathrm{C}$. 
B) was slow. Five minutes' pre-incubation at $60^{\circ} \mathrm{C}$ resulted in an increase in ALAD activity in Group B comparable to that in Group A (control), whereas the activities in Groups C and D stayed as low as that before heat treatment.

EFFECT OF TEMPERATURE AND DURATION OF HEAT TREATMENT ON ALAD ACTIVITY ALAD activity in blood from intact rabbits fell to $33-25 \%$ after a $5-$ min pre-incubation at $60^{\circ} \mathrm{C}$. The same pre-incubation increased the activity of blood ALAD after lead treatment to the level of heattreated control samples. Heat treatment caused only a slight increase after tin treatment. Results with different pre-incubation schedules are shown in Fig. 2. In Group A (control) the activity decreased with increasing temperature and with time. In Group B $(\mathrm{Pb})$, the activity increased by a factor of about 10 when the sample was heated at $60^{\circ} \mathrm{C}$ for $2.5 \mathrm{~min}$, and by a factor of about 6 when the sample was heated at $50^{\circ} \mathrm{C}$ for $20 \mathrm{~min}$; pre-incubation at $40^{\circ} \mathrm{C}$ did not produce any change in the activity. In Group D, pre-incubation at $60^{\circ} \mathrm{C}$ for $5 \mathrm{~min}$ increased activity by a factor of only $1 \cdot 4$, and pre-incubation at $50^{\circ} \mathrm{C}$ or $40^{\circ} \mathrm{C}$ did not influence activity at all.

On the 3rd day after the first injection, the $\mathrm{pH}$ dependency of blood ALAD activity was estimated, with the results shown in Fig. 3. The optimum value for control rabbits was $\mathrm{pH} 6 \cdot 8$, and for those given tin or lead, pH 5.8-6.0. After heat treatment of blood samples, the optimum $\mathrm{pH}$ in blood from tin-injected rabbits stayed at the same $\mathrm{pH}$ range as that before heat treatment, whereas that in blood from leadinjected rabbits increased to $\mathrm{pH} 6 \cdot 8$.

\section{Discussion}

In the course of experiments on the effect of different metals $(\mathrm{Pb}, \mathrm{Sn}, \mathrm{Hg}$, As and $\mathrm{Zn}$ ) on the activity of ALAD (Chiba and Kikuchi, 1974), it was noticed that tin, like lead, decreased ALAD activity. The effect of tin on porphyrin synthesis must be taken into account, therefore, when the activity of ALAD is used as a measure of lead exposure.

The effects of tin and lead on ALAD activity differ as follows: (1) recovery of ALAD activity in rabbits injected with tin is more rapid than in those injected with lead (Fig. 1); (2) heat treatment does not affect ALAD activity after tin treatment, but increases ALAD activity after lead treatment to the level of control heat-treated blood samples (Fig. 1); (3) the shift in optimum pH from $6 \cdot 8$ to $5 \cdot 8-6 \cdot 0$ is the same in tin or lead treatments, but heat treatment prevents this $\mathrm{pH}$ shift in the blood of lead-treated rabbits.

\section{References}

Chiba, M., and Kikuchi, M. (1974). Influence of the administration of lead and other metals on the activity of $\delta$ aminolevulinic acid dehydrase with and without heat treatment. Japanese Journal of Industrial Health, 16, 226-227.

Chiba, M., Tashiro, A., Nishima, T., and Kikuchi, M. (1976). Availability of activity ratio obtained from activity of 5-aminolevulinate hydro-lyase in human blood before and after heat treatment to evaluate lead exposure. Industrial Health, 14, 67-74.

De Bruin, A., and Hoolboom, H. (1967). Early signs of lead exposure. A comparative study of laboratory tests. British Journal of Industrial Medicine, 24, 203-212.

Hernberg, S., Tola, S., Nikkanen, J., and Valkonen, S. (1972). Erythrocyte $\delta$-aminolevulinic acid dehydratase in new lead exposure. Archives of Environmental Health, 25, 109-113.

Nikkanen, J., Hernberg, S., and Tola, S. (1972). Modifications of the $\delta$-aminolevulinic acid dehydratase test and their significance for assessing different intensities of lead exposure. Work-Environment-Health, 9, 46-52. 